Revista Destaques Acadêmicos, Lajeado, v. 10, n. 4, 2018. ISSN 2176-3070

DOI: http://dx.doi.org/10.22410/issn.2176-3070.v10i4a2018.2059

http://www.univates.br/revistas

\title{
OLIMPÍADA MATEMÁTICA DA UNIVATES E OFICINA DE RACIOCÍNIO LÓGICO: INTERLOCUÇÕES ENTRE ENSINO, EXTENSÃO E PESQUISA
}

Adriana Magedanz ${ }^{1}$, Márcia Jussara Hepp Rehfeldt ${ }^{2}$, Maria Madalena Dullius ${ }^{3}$, Marli Teresinha Quartieri ${ }^{4}$, Adriana Belmonte Bergmann ${ }^{5}$, Andreia Spessatto De Maman ${ }^{6}$, Jane Herber ${ }^{7}$, Sônia Elisa Marchi Gonzatti ${ }^{8}$, Carolina Pereira dos Santos $^{9}$, Eduarda Mocellin Laude ${ }^{10}$, Gustavo da Silva Melo ${ }^{11}$, Jamile Sehn ${ }^{12}$

Resumo: A Olimpíada Matemática da Univates (OMU) tem uma longa caminhada institucional. Desde 2016, o evento foi vinculado ao projeto de extensão "Redes Interdisciplinares: desvendando as Ciências Exatas e Tecnológicas" e vem sendo enriquecido por uma ação extensionista denominada Oficina de Raciocínio Lógico. Buscar apresentar a inter-relação entre OMU e Oficina de Raciocínio Lógico, enquanto

1 Licenciada em Ciências e Matemática. Doutoranda em Ensino. Professora do Cetec/Univates.

2 Licenciada em Ciências e Matemática. Doutora em Informática na Educação. Professora do Cetec/Univates.

3 Licenciada em Ciências e Matemática. Doutora em Ensino de Ciências e Matemática. Professora do Cetec/Univates.

4 Licenciada em Ciências e Matemática. Doutora em Educação. Professora do Cetec/Univates.

5 Licenciada em Ciências e Matemática. Doutoranda em Ensino. Professora do Cetec/Univates.

6 Licenciada em Ciências Exatas. Doutoranda em Ensino. UProfessora do Cetec/Univates.

7 Licenciada em Química. Doutoranda do PPG Química da Vida e Saúde - UFRGS. Professora do Cetec/Univates.

8 Graduada em Ciências. Doutora em Educação. Professora do Cetec/Univates.

9 Graduanda em Engenharia Civil - Univates. Bolsista de Extensão.

10 Graduanda em Engenharia Civil - Univates. Bolsista de Extensão.

11 Graduando em Arquitetura e Urbanismo - Univates. Bolsista de Extensão.

12 Graduanda em Design de Moda - Univates. Bolsista de Extensão. 
atividades desenvolvidas pela extensão universitária, especialmente num contexto investigativo, que envolve a percepção de estudantes da educação básica quanto ao formato das questões presentes na oficina supracitada, é o principal objetivo desta escrita. Neste sentido, o trabalho inicia por uma contextualização, exprimindo possíveis interlocuções estabelecidas no dueto OMU e Oficina de Raciocínio Lógico. Na sequência, dados oriundos de um documento utilizado durante as oficinas servem de sustentação para uma análise quanti e qualitativa, resultando em conjecturas que podem despertar revisões, reformulações ou, até mesmo, inovações no modelo atual da proposta. Por fim, a pesquisa consolida um trabalho com primícias fundamentadas exclusivamente na experiência docente e, agora, com a colaboração e cooperação dos sujeitos investigados, passa a ser revestida, também, pelo olhar dos discentes.

Palavras-chave: Educação Básica. Ensino. Extensão Universitária. Raciocínio Lógico.

\section{CONSIDERAÇÕES INICIAIS}

A Olimpíada Matemática da Univates (OMU) iniciou em 1997, a fim de estimular o interesse dos alunos pela Matemática; Durante um período esteve atrelada à OBM (Olimpíada Brasileira de Matemática); Até 2015, o evento era concebido na nossa IES (Instituição de Ensino Superior) como um projeto de extensão voltado para a organização da competição olímpica matemática. As três últimas edições, 2016 à $2018\left(19^{\mathrm{a}}, 20^{\mathrm{a}}\right.$ e $\left.21^{\mathrm{a}} \mathrm{OMU}\right)$ foram coordenadas pela equipe do projeto de extensão universitária "Redes Interdisciplinares: desvendando as Ciências Exatas e Tecnológicas" (ao longo desta escrita, a nomenclatura será abreviada como "Redes") e, desde então, "a sua finalidade vem sendo revista e algumas reformulações incrementadas, buscando contribuir na construção de diferentes saberes, não apenas o matemático" (SANTOS, 2018, p.34).

A partir deste contexto, em 2016, foi proposta uma nova ação extensionista dentro do Projeto Redes, inicialmente intitulada "Oficina da OMU" e, mais tarde, "Oficina de Raciocínio Lógico". Esta proposta é constituída por atividades que possibilitam explorar "o raciocínio lógico e a criatividade, essenciais no processo de resolução de problemas de qualquer área" do conhecimento, buscando despertar nos envolvidos, estudantes do Vale do Taquari/RS e arredores, "o gosto pelo conhecimento científico e contribuindo para um aprendizado menos burocrático e mecânico", a partir do enfoque das competições "para além de, simplesmente, um dia de prova" (SANTOS, 2018, p.34).

O objetivo deste artigo é, além de apresentar a inter-relação entre OMU e Oficina de Raciocínio Lógico no âmbito da extensão universitária, também apresentar considerações acerca da percepção dos participantes da referida oficina, no que se tange à composição e avaliação das atividades, despertando para possíveis revisões, reformulações ou, até mesmo, inovações no planejamento desta ação extensionista. 


\section{OMU e Oficina de Raciocínio Lógico: interconexões estabelecidas na extensão}

Entre os anos 2007 e 2016, cada edição da OMU contou com a participação de, aproximadamente, 2270 alunos, oriundos de 65 escolas, localizadas em 25 municípios do Vale do Taquari e arredores. O número de alunos participantes vem se mantendo nesta média, mas, no que tange à origem destes competidores, esta estatística é crescente, já que em 2017 participaram 74 escolas localizadas em 26 diferentes municípios do Vale e arredores e, em 2018, 78 escolas, envolvendo 27 municípios. É perceptível que a abrangência geográfica da OMU está em expansão.

Desde a primeira edição, as provas da Olimpíada sempre foram elaboradas por uma equipe de professores da Univates com vasta experiência em educação básica. Nesta elaboração, ao definirem uma questão integrante da prova, o grupo atenta para o nível escolar do aluno participante $\left(5^{\circ}, 6^{\circ}, 7^{\circ}\right.$, $8^{\circ}$ e $9^{\circ}$ anos do Ensino Fundamental, além do $1^{\circ}, 2^{\circ}$ e $3^{\circ}$ anos do Ensino Médio), bem como para a configuração do enunciado da atividade. Estas avaliações são compostas por 10 questões, que buscam estimular o raciocínio lógico e desafiar os alunos a inovar e pensar criativamente.

Depois da realização da prova, que ocorre em data e horário préestabelecidos, ocorre a correção destas, efetuada também por professores da Univates, e, para fins de classificação e premiação, são consideradas a dinamicidade e a criatividade nas resoluções, valorizando a apresentação do desenvolvimento das soluções. Este tipo de análise surpreende a cada ano. É eminente como os participantes da OMU vêm progredindo na qualidade das respostas descritivas (REHFELDT, 2017).

Tal aspecto pode ser influenciado por vários motivos, como retrata e exemplifica Santos (2018, p.34):

Muitos destes participantes são reincidentes, ou seja, integraram mais de uma edição. Esta sequência, em algumas situações, pode ser influenciada pela própria escola, que fomenta nos alunos o interesse por questões desafiadoras. Quando isso acontece, muitas vezes, o trabalho em sala de aula já é pautado no formato da OMU, inclusive aproveitando referenciais da área, como os Anais disponibilizados virtualmente.

Vale ressaltar que, a contar da décima sétima (17 $)$ edição, todos os anos são dispostas as publicações dos Anais da $\mathrm{OMU}^{13}$ no site da Univates, contendo as resoluções mais criativas, construídas pelos próprios participantes. Além dos contatos relacionados à busca por estes referenciais, que servem de suporte

13 Os anais contendo as resoluções das questões que compuseram a $17^{\mathrm{a}} \mathrm{OMU}, 18^{\mathrm{a}} \mathrm{OMU}, 19^{\mathrm{a}}$ OMU e $20^{a}$ OMU estão disponíveis no link <www.univates.br/editora-univates>. 
na preparação para a Olimpíada, outra observação é o aumento do número de professores que procuram a IES para agendar atividades relacionadas a este evento científico. Neste caso, o vínculo entre a OMU e a Oficina de Raciocínio Lógico se fortalece no caráter processual e de continuidade, um tipo de interação extensionista que é desejável para a universidade: manter e fortalecer os vínculos com comunidades escolares, que encontram nas ações de extensão da IES contribuições ao seu trabalho e iniciativas para motivar os estudantes na sua educação científica.

Desde sua implantação, o número de atendimentos na Oficina de Raciocínio Lógico, dentro e fora da IES, vem ganhando espaço. Utilizando o ambiente institucional, foram 84 alunos da educação básica atendidos ao longo do segundo semestre de 2016 (no primeiro semestre ocorreu a organização da referida oficina), 234 durante o ano de 2017 e $444 \mathrm{em} 2018$. Neste último ano, 2018, por solicitação de escolas, iniciou-se também esta oferta fora da IES, agregando 305 atendimentos aos 444 já existentes, ou seja, a Oficina de Raciocínio Lógico atingiu quase 750 alunos da educação básica em 2018. Se fossem consideradas neste cômputo as Mostras Científicas Itinerantes (MCIs) ${ }^{14}$, ação interdisciplinar que também integra o Projeto Redes, estes números aumentariam. Mas, para fins de análise, vamos recorrer apenas aos dados voltados exclusivamente para as oficinas não vinculadas às MCIs.

De forma resumida, a Tabela 1 permite visualizar dados quantitativos relacionadas ao histórico dos três últimos anos das ações atinentes à OMU e às oficinas. Esta estatística, além de apontar o aumento nos atendimentos em oficinas e uma média estável no número de participantes da OMU, retrata um aspecto pertinente à Política Nacional de Extensão Universitária (2012): a interrelação existente entre comunidades e universidade consolidada.

Tabela 1 - Histórico de atendimentos de ações vinculadas à OMU e às oficinas

\begin{tabular}{c|c|c|c|c|c|c}
\hline & $\mathbf{2 0 1 6}$ & $\mathbf{2 0 1 7}$ & \multicolumn{2}{|c|}{$\mathbf{2 0 1 8}$} & TOTAL em 3 anos & MÉDIA/ano \\
\hline \multirow{2}{*}{$\begin{array}{c}\text { Oficinas de } \\
\text { Raciocínio Lógico }\end{array}$} & IES & IES & IES & Externa & IES e Externa & IES e Externa \\
\cline { 2 - 7 } & 84 & 234 & 444 & 305 & 1067 & 356 \\
\hline Participantes OMU & 2324 & 2228 & \multicolumn{2}{|c|}{2246} & 6798 & 2266 \\
\hline
\end{tabular}

Fonte: Dos autores (2018), com base no arquivo de controles internos do Projeto Redes.

14 Mostras Científicas Itinerantes (MCIs): Consistem em atividades simultâneas - oficinas e planetário - realizadas em um ou dois dias, nas instituições interessadas, que se inscrevem e participam de processo seletivo específico, no início do ano letivo (GONZATTI e HERBER, 2018, p.11). 
Com relação à organização da Oficina de Raciocínio Lógico ${ }^{15}$, é importante esclarecer que a atividade está dividida em quatro categorias, alicerçada no estilo das provas da OMU, são elas: muito fácil (ou nível A), fácil (ou nível B), médio (ou nível C) e difícil (ou nível D). Na sequência, optou-se em ilustrar um exemplo de cada estrato.

2.1 Nível A: Esta categoria é composta por cinco atividades "muito fáceis" diferentes das quais, normalmente, são selecionadas duas ou três em cada oficina. Uma delas, visualizada na Imagem 1, envolve palitos, que são disponibilizados aos alunos para que construam as imagens evidenciadas nos cartões concedidos e complementem com o solicitado. Neste exemplo, o enunciado expresso na cartela é: Construa a imagem abaixo com o material recebido. Após, reposicione três palitos para formar três triângulos exatamente iguais.

Imagem 1 - Exemplificação de questão presente no Nível A

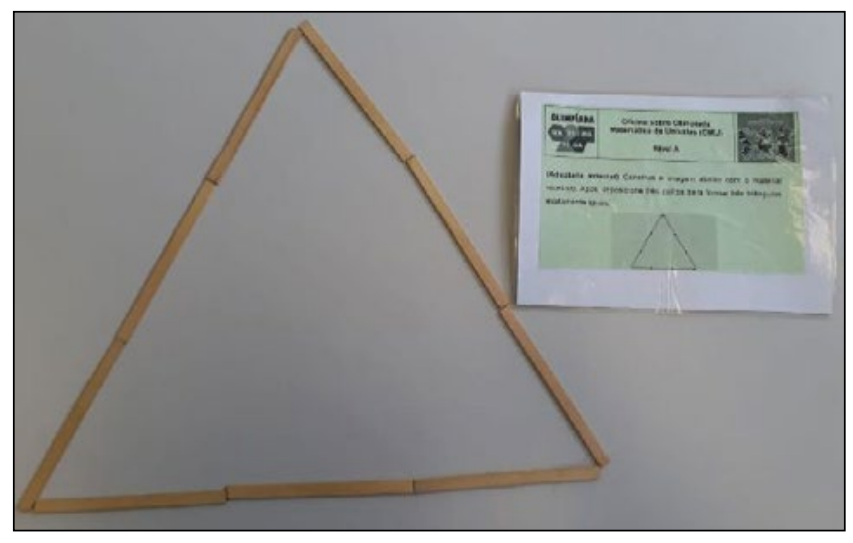

Fonte: Dos autores (2018), a partir do arquivo de fotos do projeto Redes.

As questões do Nível A, eventualmente, podem ser adaptadas para suprir necessidades dos participantes.

2.2 Nível B: Esta categoria é composta por oito atividades "fáceis" diferentes das quais, normalmente, são selecionadas três ou quatro em cada oficina. Uma delas, visualizada na Imagem 2, é de múltipla escolha e estimula os alunos a buscarem uma possível solução para o problema, "alternando o pensamento analítico e sistêmico" (MAGEDANZ, 2018, p.84). Neste exemplo, o enunciado expresso na cartela é: As duas peças idênticas recebidas podem ser deslocadas e rodadas sem que sejam levantadas da mesa. Nessas condições, qual

15 A descrição detalhada da Oficina de Raciocínio Lógico está presente no capítulo 6 da obra "Articulações possíveis entre Ensino e Extensão: Experiências pedagógicas do projeto Redes Interdisciplinares", disponível no link<www.univates.br/editora-univates/publicacao/248>. 
das figuras abaixo não pode ser montada com essas duas peças? - Nas opções são apresentadas cinco imagens, onde apenas a letra " $\mathrm{d}$ " não permite montagem.

Imagem 2 - Exemplificação de questão presente no Nível B

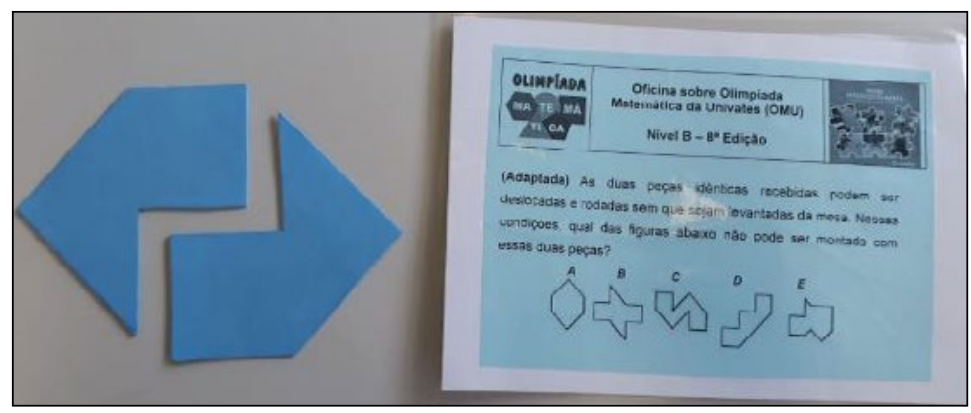

Fonte: Dos autores (2018), a partir do arquivo de fotos do projeto Redes.

Na busca pela solução, é fundamental atentar para a regra estabelecida no enunciado: as duas peças não podem ser içadas da base onde estão dispostas porque, se pudessem, inclusive a letra " $\mathrm{d}$ " seria possível montar.

2.3 Nível C: Esta categoria é composta por sete atividades "intermediárias" diferentes das quais, normalmente, são selecionadas duas ou três em cada oficina. Uma delas, visualizada na Imagem 3, apresenta um desafio que tem como objetivo desenvolver o raciocínio lógico e a capacidade de observação em escala tridimensional. Neste exemplo, o enunciado expresso na cartela é: $A$ torre ao lado $(\rightarrow)$ deve ser construída com os 30 cubos de madeira recebidos. Depois da construção, imaginar que as faces exteriores da torre sejam pintadas de vermelho e, em seguida, novamente os cubos separados uns dos outros. A partir desta situação, refletir e responder: Quantos cubos teriam exatamente três faces pintadas de vermelho?

Imagem 3 - Exemplificação de questão presente no Nível C

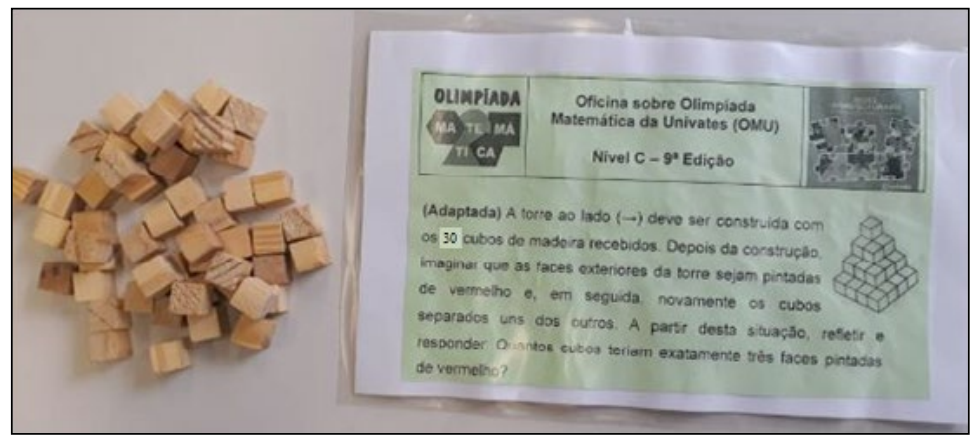

Fonte: Dos autores (2018), a partir do arquivo de fotos do projeto Redes. 
Nesta atividade, muitas vezes, é preciso ressaltar que a base inferior também é uma face exterior da torre.

2.4 Nível D: Esta categoria é composta por cinco atividades "difíceis" diferentes das quais, normalmente, são selecionadas uma ou duas em cada oficina. Uma delas, visualizada na Imagem 4, apresenta um quebra-cabeça que objetiva associar conhecimentos matemáticos e raciocínio lógico. Neste exemplo, o enunciado expresso na cartela é: Os nove triângulos menores recebidos devem ser dispostos dentro do triângulo maior, de tal forma que as relações equivalentes se correspondam.

Imagem 4 - Exemplificação de questão presente no Nível D

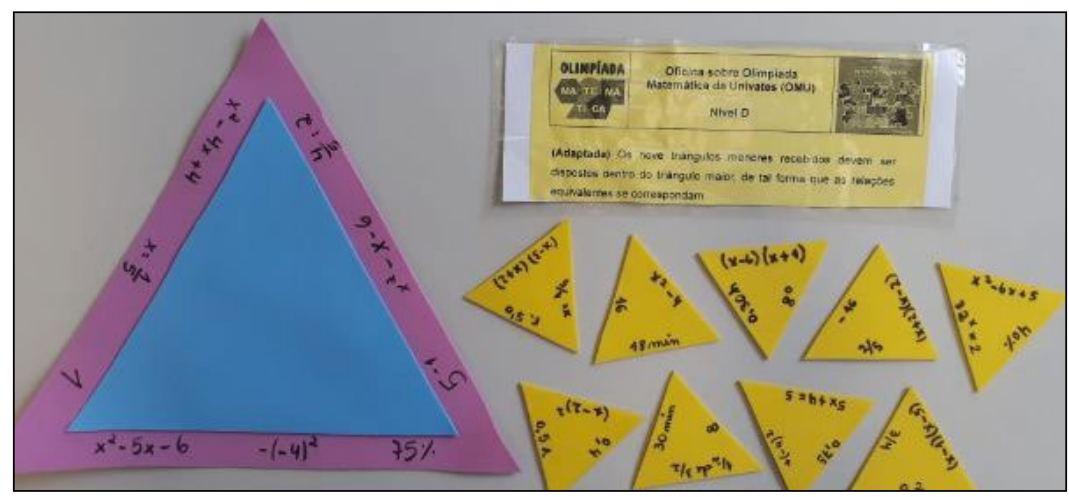

Fonte: Dos autores (2018), a partir do arquivo de fotos do projeto Redes.

Sintetizando, a classificação proposta, dividida em quatro níveis, permite contemplar os diferentes estágios de aprendizagem - educação infantil (préescola), ensino fundamental (séries iniciais e finais) e ensino médio (e técnico). É possível constatar nos exemplos que cada categoria é composta por um rol de questões (organizadas em cartelas) e diversos materiais concretos (palitos, cubinhos, etc), para auxiliar nas soluções (MAGEDANZ, 2018). A Imagem 5 ilustra, resumidamente, todas estas definições. 
Imagem 5 - Distribuição das categorias (níveis A, B, C e D), cartelas com enunciado das questões e material concreto para resolução

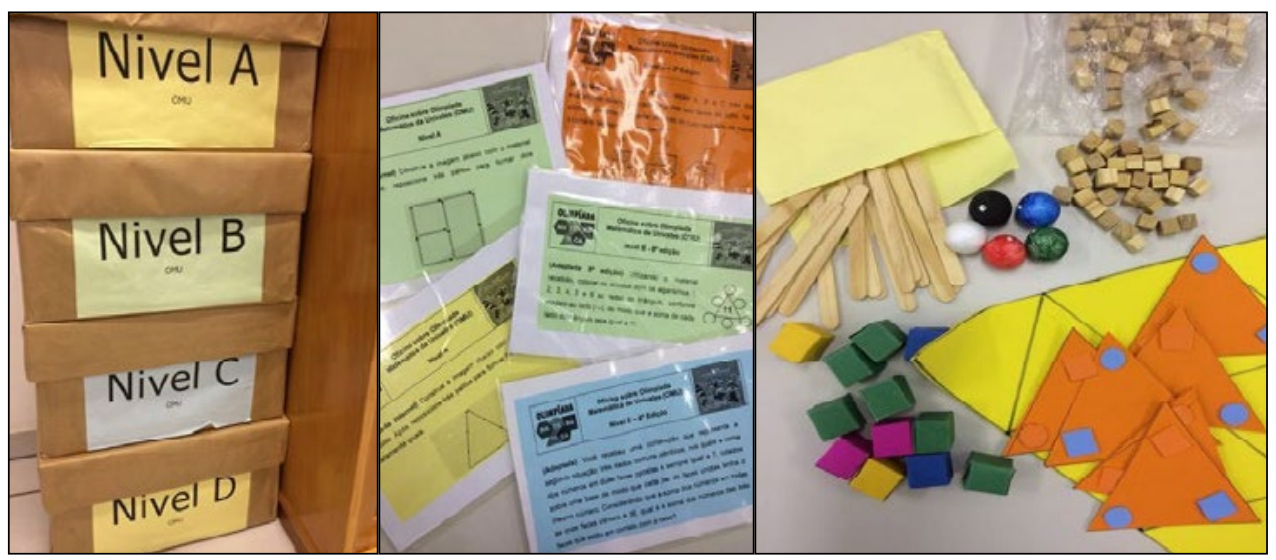

Fonte: Dos autores (2018), a partir do arquivo de fotos do projeto Redes.

A conjuntura apresentada até aqui permite vislumbrar a OMU como uma atividade que, para inúmeros participantes, atualmente, perpassa o momento da competição, já que está explícita toda uma preparação anterior na comunidade escolar, que acaba culminando com o dia da prova. Santos (2018, p.34) evidencia tal aspecto:

Quanto ao desempenho de cada aluno na Olimpíada, o que se percebe na fala informal de alguns participantes é que a cada ano existe um desejo de melhorar a performance do ano anterior e, assim, no ano seguinte, o ciclo de preparação se reinicia e, para àqueles competidores que já acumularam alguma experiência, a OMU deixa o status de "evento de um dia" e passa a ser concebida como parte de um processo pedagógico.

Fortalecendo esta ideia de "promover uma forma desafiadora e lúdica de aprender, além de estimular o raciocínio, a lógica e a criatividade" (MAGEDANZ, 2018, p.77), tão presente no desenvolvimento de atividades pedagógicas atreladas à $\mathrm{OMU}$, como, por exemplo, a Oficina de Raciocínio Lógico, está a possibilidade de munir os alunos da educação básica de artifícios diversificados na resolução de diferentes tipos de problemas, contribuindo com a premissa de "traçar uma estratégia ou plano para resolver a questão" (MASSI, p.49, livro digital).

Nesta ótica, investir no desenvolvimento da "Oficina de Raciocínio Lógico" e na participação da "Olimpíada Matemática da Univates" se configura como oportunidades de ensino e de aprendizagem coletivos, tanto no que se refere ao formato que é utilizado nas duas ações, as quais oportunizam as resoluções das tarefas propostas em equipe, quanto pela possibilidade de 
vivências e aproximações entre os sujeitos envolvidos (docentes e discentes). Tais aspectos contribuem para a mobilização da comunidade acadêmica também num contexto investigativo, reforçando "o princípio constitucional da indissociabilidade entre ensino, pesquisa e extensão" (FORPROEX, 2012, p.28). Isto posto, passamos a abordar outro ponto que motivou esta reflexão: a percepção dos participantes da Oficina de Raciocínio Lógico sobre a composição e avaliação das atividades.

\section{Oficina de Raciocínio Lógico: potencial investigativo}

Ao fundamentar teoricamente o contexto explorado nas atividades propostas durante a Oficina de Raciocínio Lógico, podemos incluir referenciais que contemplem ensino, pesquisa e extensão (ALMEIDA e SAMPAIO, 2010; FORPROEX, 2012; GONZATTI e HERBER, 2018; GONZATTI et al., 2018; SÍVERES, 2008; 2013; UNIVATES, 2015), didática da Matemática (GROENWALD, 1997; NETO, 2001), interdisciplinaridade (FAZENDA, 2016; JAPIASSU, 1976; KETZER, 2007; LUCK, 2003; PATARO e BOVO, 2012; THIESEN, 2008), olimpíadas matemáticas (HAETINGER, 2012; SANTOS, 2018), raciocínio lógico (CARVALHO e CAMPOS, 2016; LIMA, 2010; PADILHA, 2012; SÉRATES, 1998; 2004), resolução de problemas e suas estratégias (DANTE, 1989; 2002; 2010; ECHEVERRÍA e POZO, 1998; FURLANETTO, 2013; MASSI, livro digital; POLYA, 1978; POZO, 1998; REHFELDT, 2017; SMOLE e DINIZ, 2001).

Diante de tão vasta iluminação teórica, é possível vislumbrar o potencial investigativo decorrente desta ação extensionista. Assim, ao incentivar o desenvolvimento de atividades que apontam para a socialização do conhecimento, com papel fundamental e estratégico para promover e divulgar a cultura científica, acaba-se desencadeando uma espécie de retroalimentação entre Universidade e comunidade, viabilizando possíveis discussões que contribuirão para a melhoria de aspectos pedagógicos importantes.

Enquanto pesquisa, a produção científica específica em torno das estratégias usadas pelos alunos - socializadas anualmente nos Anais ${ }^{16}$, sobre conjuntos de conteúdos que apresentam maior ou menor dificuldade - explorado por Rehfeldt (2017), ou sobre as particularidades presentes na avaliação pessoal dos participantes - objeto de análise neste artigo, pode ser compreendida como contribuições deste processo que reverbera nas práticas escolares. Investigar, por sua vez, exige formas de registro e instrumentos adequados para o recolhimento de dados, que tanto subsidiam a produção de conhecimento quanto o feedback avaliativo das ações. Nesta dinâmica, em que as ações de extensão interagem e reverberam no âmbito do ensino escolar, ao mesmo tempo em que se constituem como campo de produção

16 Idem nota de rodapé número 13. 
de conhecimento, estabelece-se um ciclo relacional entre ensino, extensão e pesquisa, que concretiza o princípio da indissociabilidade, diretriz fundamental do Ensino Superior nos contextos atuais.

Considerando o exposto, optou-se, neste trabalho, em limitar a análise de dados à interpretação das respostas de duas perguntas presentes num documento utilizado ao longo de todas as oficinas de raciocínio lógico realizadas. Este instrumento, respondido por cada um dos grupos participantes, é constituído de dez espaços para ilustrar as soluções dos problemas propostos e, ao final, das duas seguintes perguntas: "O que vocês mais gostaram na oficina? Qual a questão que o grupo mais gostou? Por quê?"; "O que vocês menos gostaram na oficina? Qual a questão que o grupo menos gostou? Por quê?". A Imagem 6 apresenta o documento de registro utilizado.

Imagem 6 - Modelo de documento utilizado em cada oficina

\begin{tabular}{|c|c|c|}
\hline OLIMPIADA & \multirow{2}{*}{$\begin{array}{c}\text { Oficina de Raciocínio Lógico } \\
\text { Folha de resoluçōes e } \\
\text { questionário }\end{array}$} & $\begin{array}{l}\text { INTERDISCDESINANARS } \\
\text { IN }\end{array}$ \\
\hline $\begin{array}{l}\text { MA TE MA } \\
\text { TI CA }\end{array}$ & & $\sec { }^{2} p$ \\
\hline \multicolumn{2}{|l|}{ Questão 1} & Questão 2 \\
\hline \multicolumn{2}{|l|}{ Questão 3} & Questão 4 \\
\hline \multicolumn{2}{|l|}{ Questão 5} & Questão 6 \\
\hline \multicolumn{2}{|l|}{ Questão 7} & Questão 8 \\
\hline \multicolumn{2}{|l|}{ Questão 9} & Questão 10 \\
\hline \multicolumn{3}{|c|}{ O que vocês mais gostaram na oficina? Qual a questão que o grupo mais gostou? Por quê? } \\
\hline \multicolumn{3}{|c|}{ O que vocês menos gostaram na oficina? Qual a questão que o grupo menos gostou? Por quê? } \\
\hline
\end{tabular}

Fonte: Arquivo do Projeto Redes (2018).

Somaram-se, aproximadamente, 600 documentos analisados. Inicialmente, buscou-se apenas mapear, quantitativamente, as atividades mais citadas nas respostas da primeira pergunta - aquelas que o grupo "mais 
gostou", bem como as da segunda pergunta - aquelas que o grupo "menos gostou". Metodologicamente, este aspecto quantitativo vem ao encontro da objetividade proposta por Gerhardt e Silveira (2009, p.34), averiguando o montante alcançado em cada situação e a representatividade do mesmo na conjectura a ser analisada.

O Gráfico 1 permite visualizar este cenário. Na interpretação deste gráfico, é importante atentar para algumas observações: foram computadas de forma individual apenas atividades que alcançaram trinta (30) ou mais citações; no total eram vinte e cinco (25) diferentes atividades, das quais somente oito (8) tiveram algum tipo de destaque na pesquisa (mais de 30 citações); as atividades, para fins de representação, foram aqui identificadas como A, B, C, D, E, F, G e H; em média, cada grupo atendido na oficina realiza dez (10) atividades de diferentes categorias e a escolha destas varia de acordo com o nível de ensino; os votos destinados as dezessete (17) atividades não presentes no gráfico foram totalizados numa opção denominada "Outros". Nas duas questões analisadas apareceu a resposta "gostamos de tudo", o que implica numa categoria independente; encontrou-se, para uma mesma pergunta, mais de uma atividade citada (neste caso, foram agregadas cada uma das citações, de forma individual).

Gráfico 1 - Comparativo gráfico das respostas referentes ao "gostar" ou "não gostar" de uma atividade da Oficina de Raciocínio Lógico

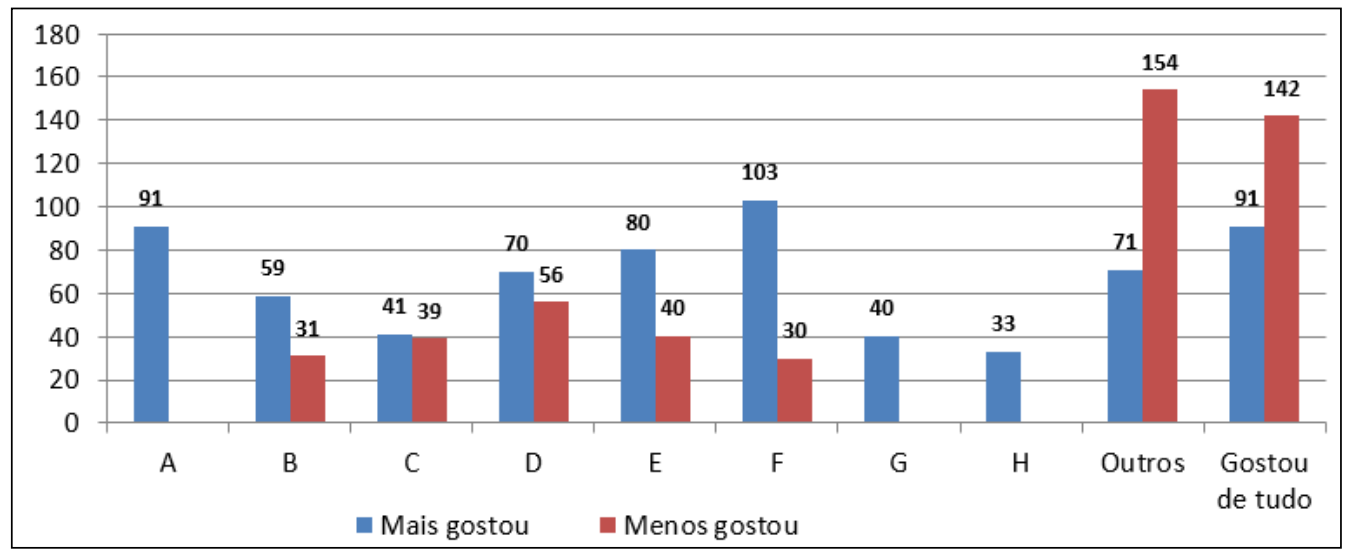

Fonte: Dos autores (2018).

A partir desta visualização inicial, já é possível ensaiar alguns questionamentos, como: Qual a característica das atividades A, G e H, uma vez que somente receberam votos do tipo "mais gostou"? Por que a atividade $\mathrm{C}$ teve o menor índice de discrepância? $\mathrm{O}$ que pode ter influenciado no alto número de votos na opção "gostou de tudo", seja na pergunta referente ao que "mais gostou" ou ao que "menos gostou"? Como a atividade F conseguiu 
tantos adeptos, acumulando o maior número individual dos votos da opção "mais gostou"?

É perceptível que os quantitativos apresentados são significativos. Mas, como a meta proposta inicialmente está voltada para a percepção dos participantes quanto à composição e avaliação das atividades, a ideia é adentrar em outra vertente de análise, interpretando também as justificativas expostas em cada questão, buscando associar à cada atividade escolhida (visível no Gráfico 1) o porquê da sua escolha.

Assim, algumas considerações são pertinentes e merecem discussão no aspecto qualitativo. Com relação à interpretação destes dados, que poderia configurar numa fase de pré-análise de conteúdo difundida por Bardin (2011, p. 125), buscou-se verificar a justificativa mencionada pelos respondentes ao citar a atividade. Para auxiliar nesta etapa, foram geradas nuvens de palavras ${ }^{17}$, as quais destacam os termos que foram mais incidentes, mostrando-os em tamanho maior. O ponto de corte para o filtro utilizado, conforme quadro que acompanha a nuvem, foi a ocorrência de mais de 20 repetições na palavra. A Imagem 7 retrata o resultado pertinente à justificativa dos respondentes para as duas perguntas: a primeira, que se refere as atividades que o grupo "mais gostou", e a segunda, as que "menos gostou".

17 A geração das "nuvens de palavras" foi realizada com auxílio de um aplicativo online, denominado WordArt e disponível em <wordart.com>. 
Imagem 7 - Conjunto de palavras presentes nas justificativas dos respondentes

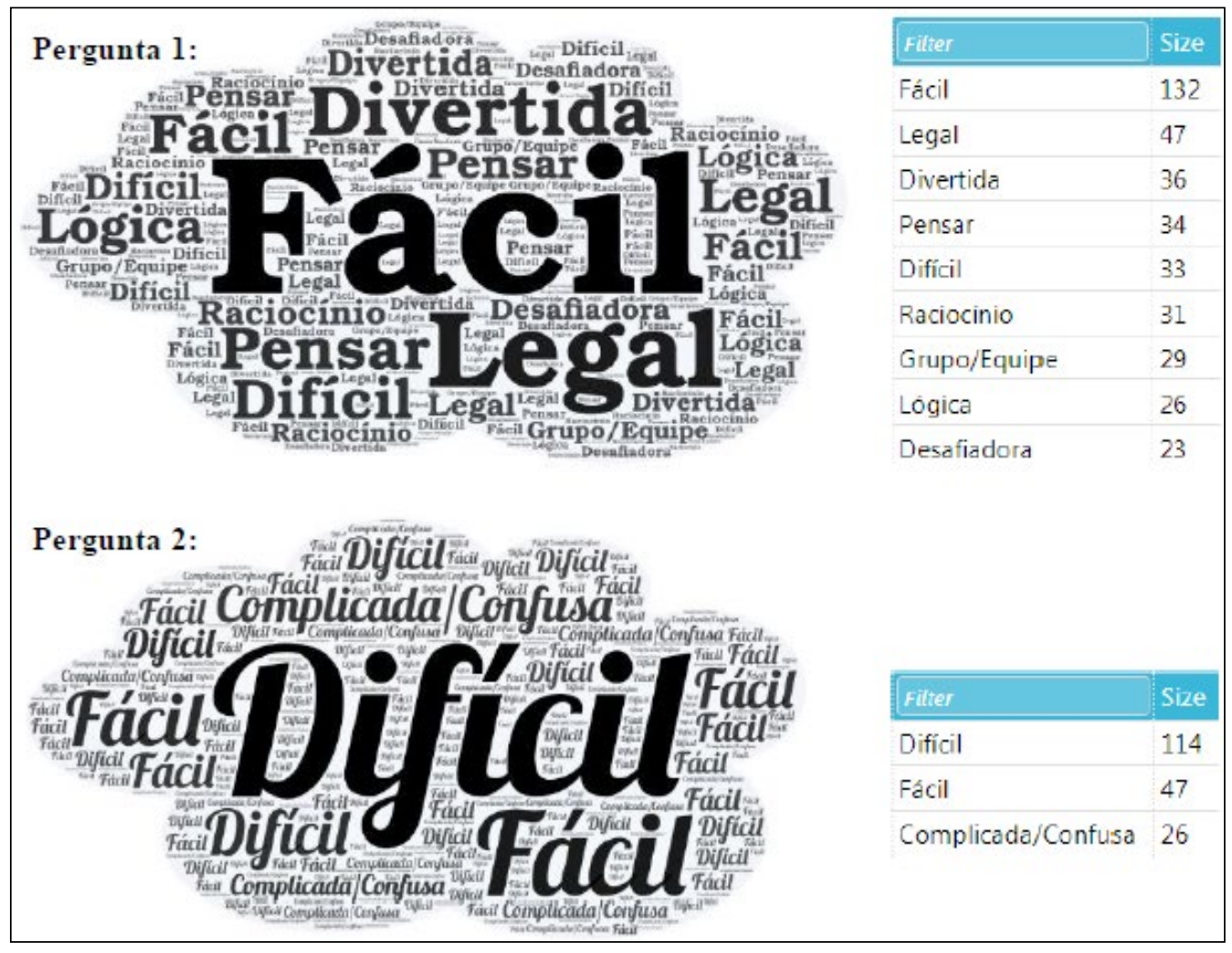

Fonte: Dos autores (2018).

De forma geral, os respondentes "mais gostaram" do que julgaram "fácil" e menos gostaram do que, para eles, era "difícil". Num primeiro momento, esta conclusão é pouco significativa. Mas, ao retornar à classificação inicial das atividades, estabelecida pelos elaboradores da oficina com base exclusivamente na experiência enquanto docentes, ela aparece distribuída em quatro categorias: muito fácil (ou nível A), fácil (ou nível B), médio (ou nível C) e difícil (ou nível D). Considerando este fator, é importante agregar outro dado a esta análise: as atividades identificadas no estudo de A, B e C integram a classificação muito fácil; D, E, F e G estão no rol das fáceis; e, das mais citadas, apenas $\mathrm{H}$ é considerada pelos elaboradores como sendo de nível intermediário (médio). Assim, revisando o Gráfico 1, a concentração da opção "mais gostou" se dá nas atividades de A até G, somando 484 votos (de um total de 679), ou seja, em torno de $71 \%$ das respostas pactuam com a classificação pré-estabelecida, afinal, definiram como "fáceis" o que de fato está sendo considerado na organização das atividades da oficina como tal. Por outro lado, a opção "menos gostou", embora com representações diluídas em B, C, D, E e F, tem um acúmulo representativo de votantes na coluna "outros", 
que representa, basicamente, as atividades que compõem as categorias médio e difícil. Mais uma vez a percepção dos participantes vem ao encontro das definições especificadas para a oficina pelos professores organizadores. Para fins da análise aqui proposta, não foram considerados os votos que se concentram na última coluna do Gráfico 1 ("gostou de tudo").

Ao optar pela interpretação dos dados no contexto da análise de conteúdo de Bardin (2011), é possível ratificar em Santos e Dalto $(2012$, p.3) as etapas deste processo: "a partir de dados qualitativos" (respostas das perguntas presentes no documento utilizado nas oficinas), "realiza-se um agrupamento quantitativo" (criação das nuvens de palavras com os termos mais presentes nas respostas) "que possibilita uma análise qualitativa novamente" (comparativos que conduzem as discussões dos resultados). Por fim, diante dos fatores que, inicialmente, motivaram essa escrita, verifica-se que o conteúdo apresentado permite vislumbrar elementos satisfatórios para propor algumas reflexões.

\section{CONSIDERAÇÕES FINAIS}

Em 2018, o Projeto Redes completa três (3) anos de existência. A Oficina de Raciocínio Lógico agrega na sua caminhada este mesmo período. Já a Olimpíada Matemática da Univates (OMU) acumula 21 anos. Neste intervalo de tempo, buscou-se contemplar o conceito de extensão universitária relacionado ao princípio de aprendizagem, extrapolando vivências e saberes, trazendo contribuições intra e interpessoais, perpassando aspectos profissionais e sociais, conectando saberes e trilhando veredas menos disciplinares. Hoje, ainda não é possível determinar um parâmetro para mensurar os impactos de ações extensionistas desta natureza, seja na formação escolar, na carreira profissional ou na vida pessoal dos participantes. A própria política nacional de extensão (FORPROEX, 2012) assinala como um desafio desenvolver e aprimorar os processos de avaliação e os indicadores para a extensão universitária.

Além de apresentar possíveis interlocuções entre ensino, extensão e pesquisa, a análise apresentada neste artigo promove reflexões relevantes sobre a concepção e classificação das questões que compõem a Oficina de Raciocínio Lógico, a partir da percepção dos próprios participantes, estudantes da educação básica do Vale do Taquari e arredores. De maneira geral, ao acompanhar a realização destas duas ações extensionistas - oficina e OMU - percebe-se um estímulo para resolver as atividades propostas, assim como se destaca o aspecto motivacional muito presente naqueles que integram as olimpíadas. Possivelmente, a palavra-chave mobilizadora nestes dois cenários seja o desafio, que instiga os estudantes a pensarem, debaterem e argumentarem com pensamento mais livre e criativo, algo nem sempre presente no Ensino de Matemática.

No que concerne especificamente à análise dos dados resultantes da investigação proposta, foi possível confirmar, nas respostas expressas pelos 
respondentes do documento utilizado na pesquisa, que o perfil das atividades está de acordo com o estabelecido pelos elaboradores da mesma e, com isso, fortalecer aspectos relacionados a esta organização. Tais constatações não descartam possíveis revisões, reformulações ou, até mesmo, inovações na versão original da oficina. Porém, consolidam um trabalho que, inicialmente, havia sido concebido, fundamentado e definido basicamente na experiência pedagógica de docentes e, agora, vem revestida pela inserção de novos olhares, aguçando princípios colaborativos e cooperativos na ação extensionista apresentada.

\section{REFERÊNCIAS}

ALMEIDA, L. P. de; SAMPAIO, J. H. Extensão universitária: aprendizagens para transformações necessárias no mundo da vida. Revista Diálogos: construção conceitual de extensão e outras reflexões significativas. Brasília, v. 14, n.1, dez/2010, p. 33-41. Disponível em: <portalrevistas.ucb.br/index.php/RDL/article/ view/2926/1836>. Acesso em: 28/11/2018.

BARDIN, L. Análise de conteúdo. Tradução Luís Antero Reto, Augusto Pinheiro. SãoPaulo: Edições 70, 2011.

CARVALHO, S.; CAMPOS, W. Raciocínio lógico simplificado. 2. ed. Salvador: Juspodivm, 2016.

DANTE, L. R. Didática da Resolução de Problemas. São Paulo: Ática, 1989.

Didática da resolução de problemas de matemática: 1. a 5. séries. 12. ed. São Paulo: Ática, 2002.

. Formulação e resolução de problemas de matemática: teoria e prática. Ensino fundamental: $1^{\circ}$ ao $5^{\circ}$ ano. São Paulo: Ática, 2010.

ECHEVERRÍA, M. D. P. P.; POZO, J. I. Aprender a resolver problemas e resolver problemas para aprender. Porto Alegre: Artes Médicas, 1998.

FAZENDA, I. C. A. Interdisciplinaridade: história, teoria e pesquisa. $18^{\mathrm{a}} \mathrm{ed}$, Campinas, SP: Papirus, 2016 (6 ${ }^{a}$ reimpressão).

FORPROEX - Fórum de Pró-Reitores de Extensão das Universidades Públicas Brasileiras. Política Nacional de Extensão Universitária. Manaus, 2012. Disponível em: <www.ufmg.br/proex/renex/images/documentos/Pol\%C3\%ADtica-Nacionalde-Extens\%C3\%A3o-Universit\%C3\%A1ria-e-book.pdf>. Acesso em: 24/11/2018.

FURLANETTO, V. Explorando estratégias diferenciadas na resolução de problemas matemáticos. 2013. 121 f. f. Dissertação apresentada ao Programa de Pós-Graduação em Ensino de Ciências Exatas do Centro Universitário UNIVATES, como exigência parcial para obtenção do grau de Mestre em Ensino de Ciências Exatas, na linha de 
pesquisa Tecnologias, Metodologias e Recursos Didáticos para o Ensino de Ciências e Matemática.

GERHARDT, T. E.; SILVEIRA, D. T. (orgs) Métodos de pesquisa. Porto Alegre: Editora da UFRGS, 2009.

GONZATTI, S. E. M.; HERBER, J. (orgs.) Articulações Possíveis entre Ensino e Extensão: Experiências pedagógicas do projeto Redes Interdisciplinares. Lajeado: Ed. Univates, 2018.

GONZATTI, S. E. M. et al. Projeto de extensão "Redes Interdisciplinares: Desvendando as Ciências Exatas e Tecnológicas" - contribuições na qualificação da formação discente. In: DALMOLIN, B. M. et al. (orgs.) Forext: a extensão universitária no protagonismo e na qualificação da formação do estudante. Coletânea do Fórum Nacional de Extensão e Ação Comunitária das Universidades e Instituições de Ensino Superior Comunitárias. Passo Fundo: Ed. Universidade de Passo Fundo, 2018. p.136-159.

GROENWALD, C. L. O. Educação matemática de 5. a 8. séries do 1. grau: uma abordagem construtivista. [S.1.]: Salamanca, 1997.

HAETINGER, C. et al. Olimpíadas Matemáticas do Centro Universitário

UNIVATES: questões e melhores soluções da 6a. à 13a. edição. Curitiba: CRV, 2012.

JAPIASSU, H. Interdisciplinaridade e patologia do saber. Rio de Janeiro: Imago Editora: 1976.

KETZER, S. M. Ensinar e aprender no jogo da interdisciplinaridade. In: AUDI, J. L. N.; MOROSINI, M. C. Inovação e interdisciplinaridade na Universidade. Porto Alegre: EDIPUCRS, 2007, p. 91-100.

LIMA, M. Matemática e raciocínio lógico FCC: questões de concursos com gabarito e comentadas. Rio de Janeiro: Elsevier, 2010.

LUCK, H. Pedagogia interdisciplinar: fundamentos teórico-metodológicos. 11. ed. Petrópolis, RJ: Vozes, 2003.

MAGEDANZ, A. et al. Oficina de raciocínio lógico: socializando o contexto. In: GONZATTI, S. E. M.; HERBER, J. (orgs.) Articulações Possíveis entre Ensino e Extensão: Experiências pedagógicas do projeto Redes Interdisciplinares. Lajeado: Ed. Univates, 2018.

MASSI, C. Como resolver provas e exercícios: Guia prático para se dar bem nas provas escolares e em concursos. CEPEFER: Livraria Online. Livro digital. Disponível em: <pt.scribd.com/doc/301715602/Como-Resolver-Provas-e-Exercicios-CosmeMassi>. Acesso em: 29/11/2018.

NETO, E. R. Didática da Matemática. 11a. edição. São Paulo: Ática, 2001.

PADILHA, J. Raciocínio lógico-matemático: teoria e aplicação. Brasília: Vestcon, 2012. 
PÁTARO, R. F. e BOVO, M. C. A interdisciplinaridade como possibilidade de diálogo e trabalho coletivo no campo da pesquisa e da educação. Revista NUPEM, Campo Mourão, v. 4, n. 6, jan./jul. 2012.

POLYA, G. A arte de resolver problemas. Rio de Janeiro: Interciencia, 1978.

POZO, J. I. (Org.). A solução de problemas: aprender a resolver, resolver para aprender. Porto Alegre: Artmed, 1998.

REHFELDT, M. J. H. et al. Uma análise das provas da olimpíada matemática: índices de erros e acertos dos alunos do ensino fundamental. In: MUNHOZ, A. V.; GIONGO, I. M. (Orgs.) Observatório da educação III: práticas pedagógicas na educação básica. Porto Alegre: Ed. Criação Humana / Evangraf, 2017. p. 182-197.

SANTOS, C. P. dos. Olimpíada Matemática da Univates: para além de um dia de prova. In: Anais- II Congresso Internacional de Ciência, Tecnologia e Conhecimento - 21 e 22 de junho de 2018. Lajeado: Ed. da Univates, 2018. Disponível em: <www. univates.br/editora-univates/media/publicacoes/261/pdf_261.pdf $>$. Acesso em: 20/12/2018.

SANTOS, J. R. V. dos; DALTO, J. O. Sobre análise de conteúdo, análise textual discursiva e análise narrativa: investigando produções escritas em Matemática. In: Anais - V Seminário Internacional de Pesquisa em Educação Matemática - 28 a 31 de outubro de 2012. Petrópolis, Rio de Janeiro. Disponível em: <www.sbembrasil.org.br / files/v_sipem/PDFs/GT08/CC03178308997_A.pdf>. Acesso em: 20/12/2018.

SÉRATES, J. Raciocínio Lógico. 8a. edição. Brasília: Ed. Jonofon Ltda., 1998.

. Raciocínio lógico: lógico matemático, lógico quantitativo, lógico numérico, lógico analítico, lógico crítico. 11. ed. rev Brasília (DF): Jonofon, 2004.

SÍVERES, L. A extensão como um princípio de aprendizagem. Revista Diálogos Universidade do Século XXI: a contribuição da extensão na busca da aprendizagem. Brasília, vol. 10, p. 8-17, 2008. Disponível em: <portalrevistas.ucb.br/index.php/RDL/ article/view/1946/1266>. Acesso em: 24/11/2018.

. (org). A Extensão universitária como um princípio de aprendizagem. Brasília: Liber Livros, 2013.

SMOLE, K. C. S.; DINIZ, M. I. (Orgs). Ler, escrever e resolver problemas: habilidades basicas para aprender matemática. Porto Alegre: Artmed, 2001.

THIESEN, J. da S. A interdisciplinaridade como um movimento articulador no processo ensino-aprendizagem. In: Revista Brasileira de Educação, v. 13, n. 39, set/ dez 2008. p. $546-554$.

UNIVATES. Plano de Desenvolvimento Institucional. Resumido. 2017-2021.

Documento interno, 2015. Disponível em: <www.univates.br/media/avaliacao/ catalogo_institucional/pdi_2017_2021-resumido.pdf>. Acesso em: 26/11/2018. 